\title{
Can Neutrophils Be a Cellular Biomarker in Asian Chronic Rhinosinusitis?
}

\author{
Dae Woo Kim (i) \\ Department of Otorhinolaryngology-Head and Neck Surgery, SMG-SNU Boramae Medical Center, \\ Seoul National University College of Medicine, Seoul, Korea
}

Chronic rhinosinusitis (CRS) is one of the most common chronic diseases having prevalence ranging from $5 \%$ to $12 \%$ and is characterized by mucosal inflammation of the nose and paranasal sinuses with nasal symptoms lasting at least 12 weeks. It proves to be a highly heterogeneous disease showing a regional difference [1].To date, the majority of CRS with nasal polyps (CRSwNP) is driven by type 2 inflammation in Western countries, whereas noneosinophilic CRSwNP is more common in Asian countries [2]. Biomarkers such as interleukin (IL)-5, periostin, and superantigens have been suggested and predict disease severity and asthma comorbidity in eosinophilic CRS, but there were no visible markers in noneosinophilic CRS [3]. Noneosinophilic CRSwNP is unlikely to be associated with asthma comorbidity and demonstrates localized characteristics but showed very diverse disease outcomes [4]. Recent studies suggested among noneosinophilic CRS, difficult-to-treat CRS is characterized by increased neutrophilic markers and shows around 50\% recurrence rate after surgery [5]. A recent study also demonstrated the imbalance of neutrophil elastase and its inhibitor, alpha1 antitrypsin is a predictor for disease refractoriness in Asian CRS [6]. Interestingly, several studies have reported that the most severe form of eosinophilic CRS shows significantly increased levels of neutrophilic markers, which are associated with reduced response to oral corticosteroid therapy [7]. These findings prompted the CRS researchers to investigate the role of neutrophils in airway inflammation. Wang et al. [8] proposed a novel mechanism by which neutrophils play a role in disease persistence and its chronic phase. IL-36 $\gamma$ and IL-36 receptor are mainly expressed by epithelial cells and neutrophils in CRS, respectively. Truncated IL-36 $\gamma$ cleaved by neutrophil elastase binds to IL-36 receptor on neutrophils and activates it to produce several inflammatory mediators such as matrix metalloproteinase 9 , IL-17A, and chemokine (C-X-C motif) ligands 8. IL-17A, in return, elicits IL-36 $\gamma$ production in epithelial cells. Products released by neutrophils such as proteases, neutrophil extracellular traps, and reactive oxygen species possesses a considerable capacity to cause nonspecific tissue destruction. However, there are limited studies indicating that neutrophils exhibit a pathologic role and associate with disease severity in CRS. Therefore, neutrophils may not be entirely pathologic and may even conduct beneficial roles in CRS. It is time to consider neutrophilic phenotype and plasticity in the context of disease severity and steroid resistance. A recent study demonstrated that CRSwNP had a neutrophilic phenotype of CD16 $6^{\text {high }}$ CD62 $\mathrm{L}^{\text {dim }}$ which had capacities to phagocytose bacteria and induce reactive oxygen species [9]. Moreover, a recent study showed that human neutrophil elastase plays a pathologic role in Asian CRS rather than myeloperoxidase [6]. Now it is increasingly recognized that the neutrophils fulfill versatile and conflicting roles in developing CRS according to each endotype [10] and need further evidence for their difference such as phenotype, location in tissues, and function.

Last but not least, the most intriguing question on neutrophil would be whether it contributes to eosinophilic inflammation or Th2 responses. Unfortunately, there are few reports on this topic in CRSwNP.Th17 response or neutrophilic inflammation is usually counteracted with Th2 but may enhance Th 2 response in the condition of mixed inflammation. Its mechanism remains unclear and should be investigated further.

\section{CONFLICT OF INTEREST}

No potential conflict of interest relevant to this article was reported.

\section{ORCID}

DaeWoo Kim https://orcid.org/0000-0001-5166-3072

Copyright (ㅇ 2019 by Korean Society of Otorhinolaryngology-Head and Neck Surgery.

This is an open-access article distributed under the terms of the Creative Commons Attribution Non-Commercial License (http://creativecommons.org/licenses/by-nc/4.0)

which permits unrestricted non-commercial use, distribution, and reproduction in any medium, provided the original work is properly cited. 


\section{REFERENCES}

1. Wang X, Zhang N, Bo M, Holtappels G, Zheng M, Lou H, et al. Diversity of $\mathrm{T}(\mathrm{H})$ cytokine profiles in patients with chronic rhinosinusitis: a multicenter study in Europe, Asia, and Oceania. J Allergy Clin Immunol. 2016 Nov;138(5):1344-53.

2. Kim DK, Eun KM, Kim MK, Cho D, Han SA, Han SY, et al. Comparison between signature cytokines of nasal tissues in subtypes of chronic rhinosinusitis. Allergy Asthma Immunol Res. 2019 Mar;11(2): 201-11.

3. Tomassen P, Vandeplas G, Van Zele T, Cardell LO, Arebro J, Olze H, et al. Inflammatory endotypes of chronic rhinosinusitis based on cluster analysis of biomarkers. J Allergy Clin Immunol. 2016 May; 137(5):1449-56.e4.

4. Kim DK, Jin HR, Eun KM, Mutusamy S, Cho SH, Oh S, et al. Noneosinophilic nasal polyps shows increased epithelial proliferation and localized disease pattern in the early stage. PLoS One. 2015 Oct; 10(10): $\mathrm{e} 0139945$.

5. Liao B, Liu JX, Li ZY, Zhen Z, Cao PP, Yao Y, et al. Multidimensional endotypes of chronic rhinosinusitis and their association with treatment outcomes. Allergy. 2018 Jul;73(7):1459-69.

6. Kim DK, Kim JY, Han YE, Kim JK, Lim HS, Eun KM, et al. Elastase- positive neutrophils are associated with refractoriness of chronic rhinosinusitis with nasal polyps in the Asian population. Allergy Asthma Immunol Res. Forthcoming.

7. Wen W, Liu W, Zhang L, Bai J, Fan Y, Xia W, et al. Increased neutrophilia in nasal polyps reduces the response to oral corticosteroid therapy. J Allergy Clin Immunol. 2012 Jun;129(6):1522-8.e5.

8. Wang H, Li ZY, Jiang WX, Liao B, Zhai GT, Wang N, et al. The activation and function of IL-36 $\gamma$ in neutrophilic inflammation in chronic rhinosinusitis. J Allergy Clin Immunol. 2018 May;141(5):1646-58.

9. Arebro J, Drakskog C, Winqvist O, Bachert C, Kumlien Georen S, Cardell LO. Subsetting reveals CD16(high) CD62L(dim) neutrophils in chronic rhinosinusitis with nasal polyps. Allergy. 2019 May 22 [Epub]. https://doi.org/10.1111/all.13919.

10. Wang H, Pan L, Liu Z. Neutrophils as a protagonist and target in chronic rhinosinusitis. Clin Exp Otorhinolaryngol. 2019 Nov;12(4): 337-47. 